\title{
Utilization of Information Technology for Non Domestic Waste Management in Semarang City
}

\author{
Muhammad $\mathrm{Ali}^{1,{ }^{*}}$, Sudharto $\mathrm{P} \mathrm{Hadi}^{1}$, and Maman Soemantri ${ }^{2}$ \\ ${ }^{1}$ Doctoral Program of Environmental Science, School of Postgraduate Studies, Diponegoro University, Semarang - Indonesia \\ ${ }^{2}$ Department of Electricall Engineering, Faculty of Engineering, Diponegoro Univers ity, Semarang - Indonesia
}

\begin{abstract}
Garbage problem is often very complex in urban areas. The handling pattern of collecting, transporting and disposing that has been applied up to this day has not yet produced an appropriate solution. This is evident from the data of statistic centre institution in 2015 that $76.31 \%$ of the existing waste in the community has not been sorted, while $10.28 \%$ sorted to be used and $13.41 \%$ sorted to be discarded, showing the community amount of unsorted garbage large enough to necessitate managerial efforts at the waste sources. In designing a systematic and structured waste management system, the generations, compositions, and characteristics of the waste are indispensable. Therefore, a research is conducted on these three dimensions to the non-domestic waste in Semarang City, which involves commercial waste (from the markets, restaurants, and hotels), institutional waste (from the offices and schools ).From the research result the average of $0,24 \mathrm{kgs} /$ person/day in weight unit of the City's nondomestical waste generation is derived. The waste composition is dominated by organic waste of around $61.95 \%$, while the rest percentage is inorganic. The management policy is directed with the application of Management Information System model based on Information Technology because of the system's abilities to effectuate the waste management.
\end{abstract}

\section{Introduction}

An increase in a population will increase the amount of the waste generations. Factors causing waste generations such as lifestyle changes and the increasing varieties of consumption patterns in the community increase the volume of waste [1]. The problem of garbage in urban areas is often a very complex problem, in the manner that it requires a systematic and structured handling mechanism. The program of management at its sources which has been applied in Indonesia has not yet made a successful solution. The evidence from the Central of Statistics (BPS) data in 2015 showed that $76.31 \%$ of the existing waste in the community has not been sorted for disposal, $10.28 \%$ is sorted to be used and $13.41 \%$ is sorted to be discarded [2].

Based on its sources, garbage can be broadly grouped into domestic and non-domestic waste. The domestic waste is the waste generated from household activities or environments whereas the non-domestic waste is the waste derived commercially, industrially, or institutionally from the buildings' waste, municipal service waste, mud of sewage treatment plants and other remnants, and agricultural waste [3]. Waste that is not managed properly will cause various problems such as dirtiness, odor, disease vectors, and groundwater contamination. As a preventive measurement, it is necessary to design a waste management system.

The weaknesses in the current waste management can not be separated from the improper handlings of waste planning, implementation and supervision. One of the causes of this weakness is that the garbage management system has not been able to provide accurate information starting from handling waste at its sources, temporary shelters, and eventual final processing sites. The condition will pose difficulties to the authorities who handle the waste in formulating the policy.

The city of Semarang is currently experiencing a very rapid development, marked among others by more and more standing hotels and shopping centers as well as other infrastructural developments. Referring to Semarang's data in number of 2014, by then Semarang City already had 10 department stores, 52 supermarkets, and 47 traditional markets. The city of Semarang also had 48 hotels, 1616 schools and 126 offices. A development of a city must certainly bring benefits to the community, but behind it there also lie impacts, and one of the most visible is garbage coming from these nondomestic sources.

The method of determining and setting the number of samples of generations and compositions of cities waste in Indonesia has been arranged based on SNI-19-3964-

Corresponding author: ilamuha@yahoo.com 
1994. According to the SNI method, the determination of waste generations and compositions in the city is carried out on all sources of waste, namely domestic and nondomestic, which include commercial, institutional, municipal services (from road sweeping) and industrial waste. By knowing the generations, compositions and characteristics of waste, especially those from more representative sources, problems in waste management can be prevented and anticipated as early as possible. These data can also be used to design waste management (especially at source) and appropriate waste processing technology, so that final waste disposal to the landfill can be reduced, in accordance with the patterns the developed countries have been applying in the recent years.

This research will start from a survey to collect the data of non-domestic waste generations followed with a study to the mechanism of the waste handling system that has been applied by the city government, investigation to the weaknesses of the existing system, and consequent formulation of a proper policy direction for the waste management.

\section{Research methods}

The stage in this research includes literature studies, secondary data collections and primary field analysis, as well as data processing. Secondary data collection is available from the existing garbage data, garbage infrastructure and supporting facilities of Semarang City from BPS of Semarang city, as well as the garbage management of Semarang City Sanitation and Gardening Department, and identification of a number of facilities that produce non domestic waste.

This research is descriptive quantitative in nature, using the data from field observation and inputs from some reliable sources. Given the research basis of focusing on an object, the data collection methods therefore will be executed more with selected key informants.[4]

Primary data collection is accomplished with observation and non-domestic waste sampling. Observations made during field research are useful as additional information to support primary data in the field. Field research in the form of garbage sampling from each source of non-domestic waste to obtain data of waste generations in both weight and volume units, the compositions of the waste based on the types of the organic waste (food waste, paper, plastics, textile, rubber, yard waste, wood) and the inorganic (glass, cans, metals, etc.), compaction factors, and the specific weights of the non-domestic waste. The samplings and their measurements are based on the method SNI-193964-1994. Obtained from SNI calculation are 43 nondomestic garbage samples, which can be grouped into 8 categories of sources including 7 markets, 2 shops (grocery and photocopy shops), 5 restaurants, 5 hotels, 6 offices, 10 schools (kindergartens, elementary, junior, and senior high schools, as well as universities), 2 hospitals, 3 roads and 3 industries.

\section{Results and discussion}

\subsection{Existing condition of non-domestic waste management in Semarang city}

Handlings of the non-domestically sourced garbage, including sweeping or cleaning service in the market environments up to temporary shelters, are the responsibility of the Trade Service Office (as the market management). Waste from the TPS (temporary shelters) is transported and disposed of to the landfills (TPA/final disposal) by using trucks from the Sanitation Service. SubDistrict offices nearby markets also have temporary shelters.

The handlings of the garbage along the protocol roads, especially sweeping and collecting are carried out by the KSM (Society's Self-Help Groups) coordinated by the Head of Villages. The garbage collected along the protocol roads is then transported by the Third / Private Parties using trucks and directly disposed of to the Final Disposal. The garbage on the roads that are not cooperated with private parties are then transported by the Subdistrict's.

Semarang City Government has tried to overcome the waste. The government has optimized all existing facilities and infrastructure, making local regulations on waste. The government has also established cooperation with third parties (industrial parties) in waste processing. However, these efforts still can not handle the waste problem optimally. There is still a large amount of waste that has not been handled.

\subsection{Non-domestic waste generations}

The determination of non-domestic waste generations has considered factors of correction, compaction and recycling. The determination of waste generations is expressed in the units of weight (kgs) and volume (liters).

Table 1. Non-Domestic Waste Generations Of Semarang City

\begin{tabular}{|l|l|l|l|}
\hline No & Name Of Source & $\begin{array}{l}\text { Amount Of } \\
\text { Generation }\end{array}$ & Unit \\
\hline & Institutional & & \\
\hline 1 & Schools & 0,03 & $\mathrm{Kg} / \mathrm{p} / \mathrm{d}$ \\
\hline 2 & Offices & 0,24 & $\mathrm{Kg} / \mathrm{p} / \mathrm{d}$ \\
\hline 3 & Hospitals & 0,49 & $\mathrm{Kg} / \mathrm{p} / \mathrm{d}$ \\
\hline & Average & $\mathbf{0 , 2 5 3}$ & $\mathrm{Kg} / \mathbf{p} / \mathbf{d}$ \\
\hline & Commercials & & \\
\hline 4 & Shops & 0,23 & $\mathrm{Kg} / \mathrm{p} / \mathrm{d}$ \\
\hline 5 & Foodstalls & 0,14 & $\mathrm{Kg} / \mathrm{p} / \mathrm{d}$ \\
\hline 6 & Markets & 0,42 & $\mathrm{Kg} / \mathrm{p} / \mathrm{d}$ \\
\hline & Average & $\mathbf{0 , 2 6 3}$ & $\mathrm{Kg} / \mathbf{p} / \mathbf{d}$ \\
\hline 7 & Hotels & 0,27 & $\mathrm{Kg} / \mathrm{p} / \mathrm{d}$ \\
\hline 8 & Industries & 0.17 & $\mathrm{Kg} / \mathrm{p} / \mathrm{d}$ \\
\hline
\end{tabular}

From the primary data processing, the average of nondomestic waste generation in Semarang is $0.24 \mathrm{~kg} /$ person / day in weight unit. The biggest contributing source of waste came from hospitals waste $(0.49 \mathrm{~kg} / \mathrm{p}$ / 
d), followed by markets waste $(0.42 \mathrm{~kg} / \mathrm{p} / \mathrm{d})$. Table 1 shows the non-domestic waste generation in Semarang in $\mathrm{kg} /$ person / day.

\subsection{Non-domestic garbage generation per day}

Based on SNI-19-3964-1994 the field research was conducted eight days in a row, and from the research the non-domestic waste generation per day is obtained. Figure 3 shows the daily, non-domestic waste generation in Semarang City for each source's category.

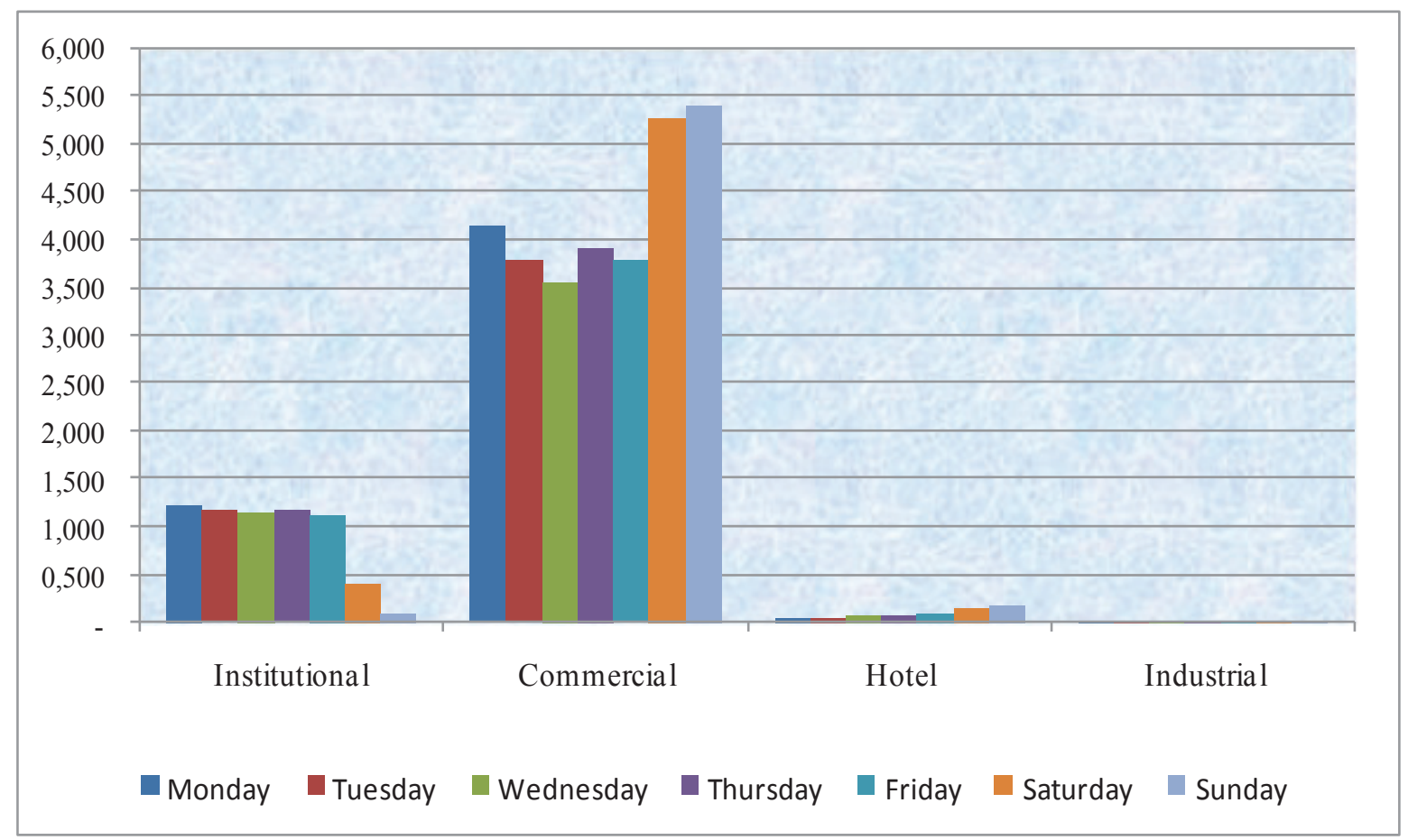

Fig 1. Non-Domestic, Daily Waste Generations Of Semarang City

The most generation of commercial waste occurs on Sundays because they are holidays, in average of about $4.6 \%$ of the total generations. In the meantime, the institutional waste generations of Semarang City increased on working days, reaching $1.2 \%$ of the total generations with a declining tendency at weekends due to the decrease of working activities during holidays. The average of the hotel-waste generations also takes increases on Sundays because not only that they are holidays but the roads facilities in front of the hotels are also used by the non inhabitants who visit Semarang City in addition to the local passers by, which produce of $0,169 \%$ of the total waste generations. In the picture above it is seen that the generation of industrial waste is almost constant due to the daily operations of productions, which is an average of $0.02 \%$ of the total existing waste generations.

\section{4 composition of non-domestic waste generations}

Waste composition is the ratio of the wet weight of a component or a type of waste to the whole waste. The result of research on the composition of the nondomestic waste in Semarang City shows that the most waste is the organic with $62 \%$ in percentage consisting of food and leaf waste, whereas the inorganic consists of $12.26 \%$ paper, $1,727 \%$ glass, $13,39 \%$ plastics and $1.8 \%$ metals, as well as $1.55 \%$ textile, $0.50 \%$ rubber, and $6.8 \%$ other waste. The composition of non-domestic waste in Semarang City can be seen in more detail in Figure 5.

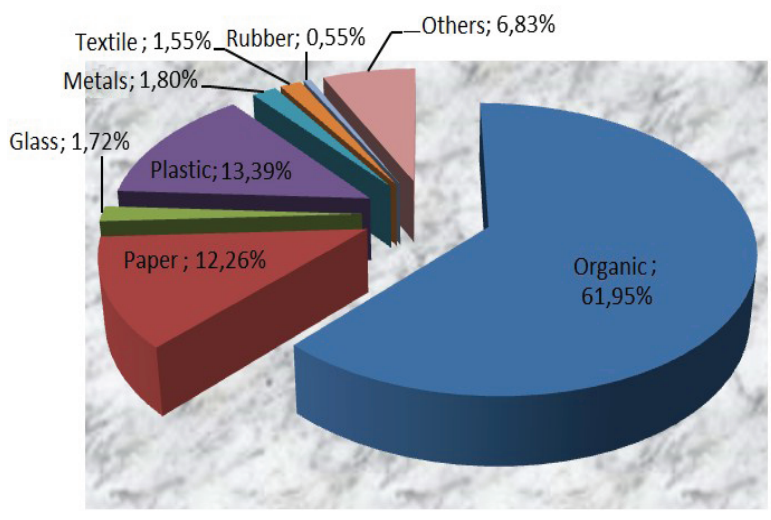

Fig 2. Composition Of Non-Domestical Waste Generations In Semarang City 


\section{5 policy direction of non-domestic waste management through the utilization of information technology}

Technology is created by men to simplify natural processing, activities, and everything that is bound to human needs. Technology is a way and an effort to improve quality of human life and to welfare it (budget funds 2013). Utilization of technology has become an important part in environmental management. Not only that technology become a tool to fulfill people's needs, but it also maintains and preserves the quality of the environment. Technology also serves to manage it, in order to remain compatible and hormonius with human life. Technological advancements have brought about shifts in human behaviors in their daily activities. Many of the human activities utilize technology either mechanically to electronically.

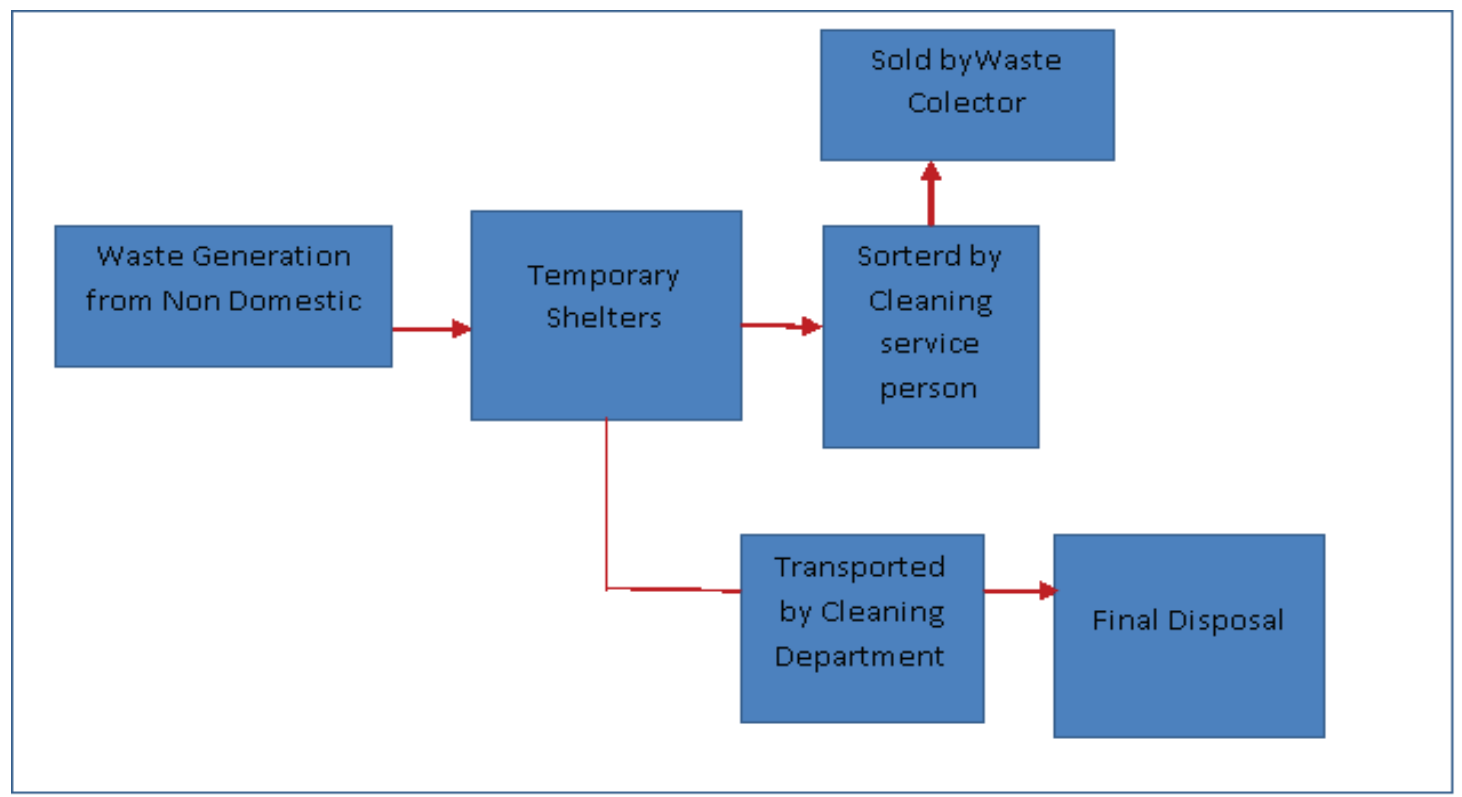

Fig 3. Exsisting of Non Domestic waste managent in Semarang City
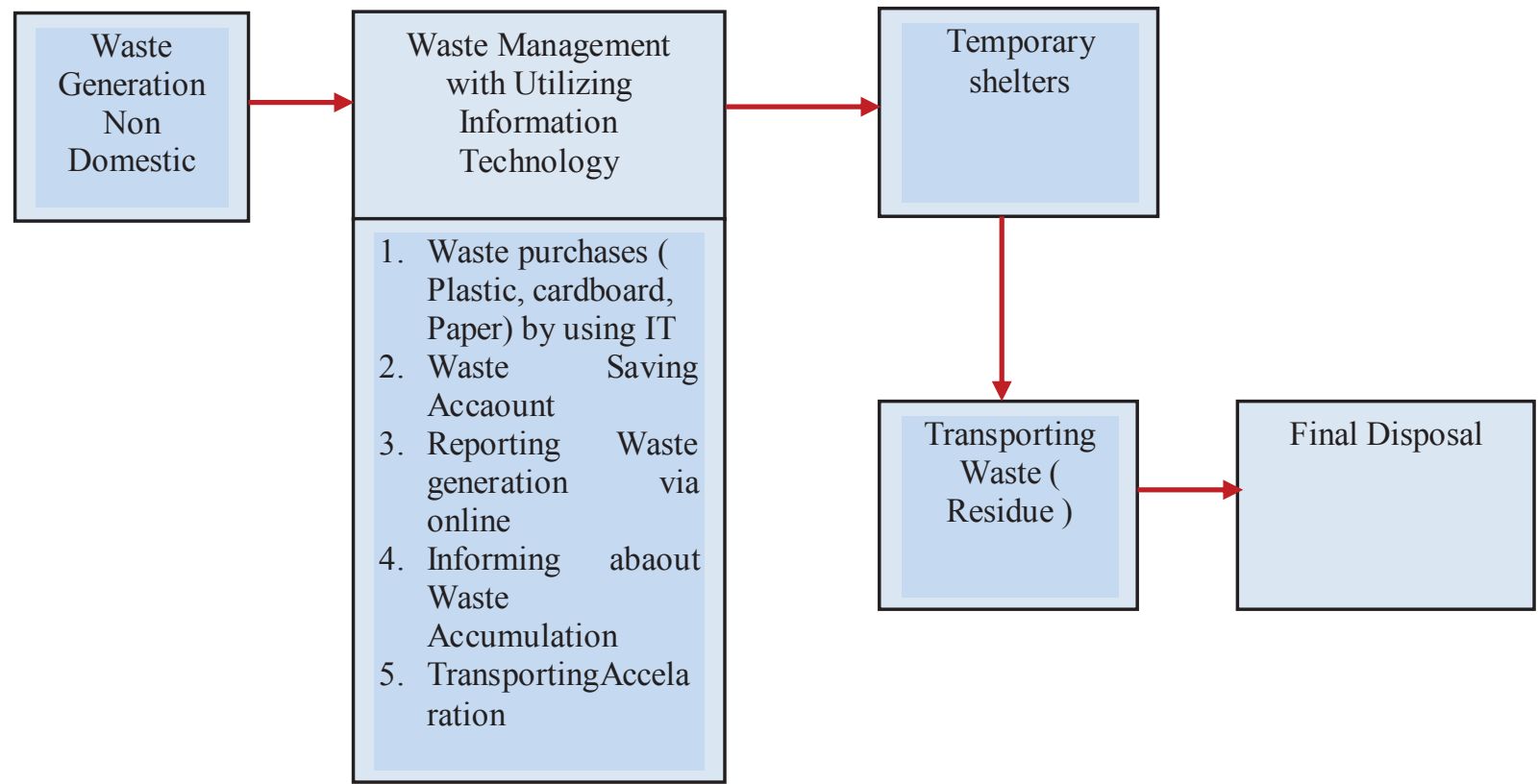

Fig 4. Plan of non domestic waste management with utilisation information technology in Semarang City 


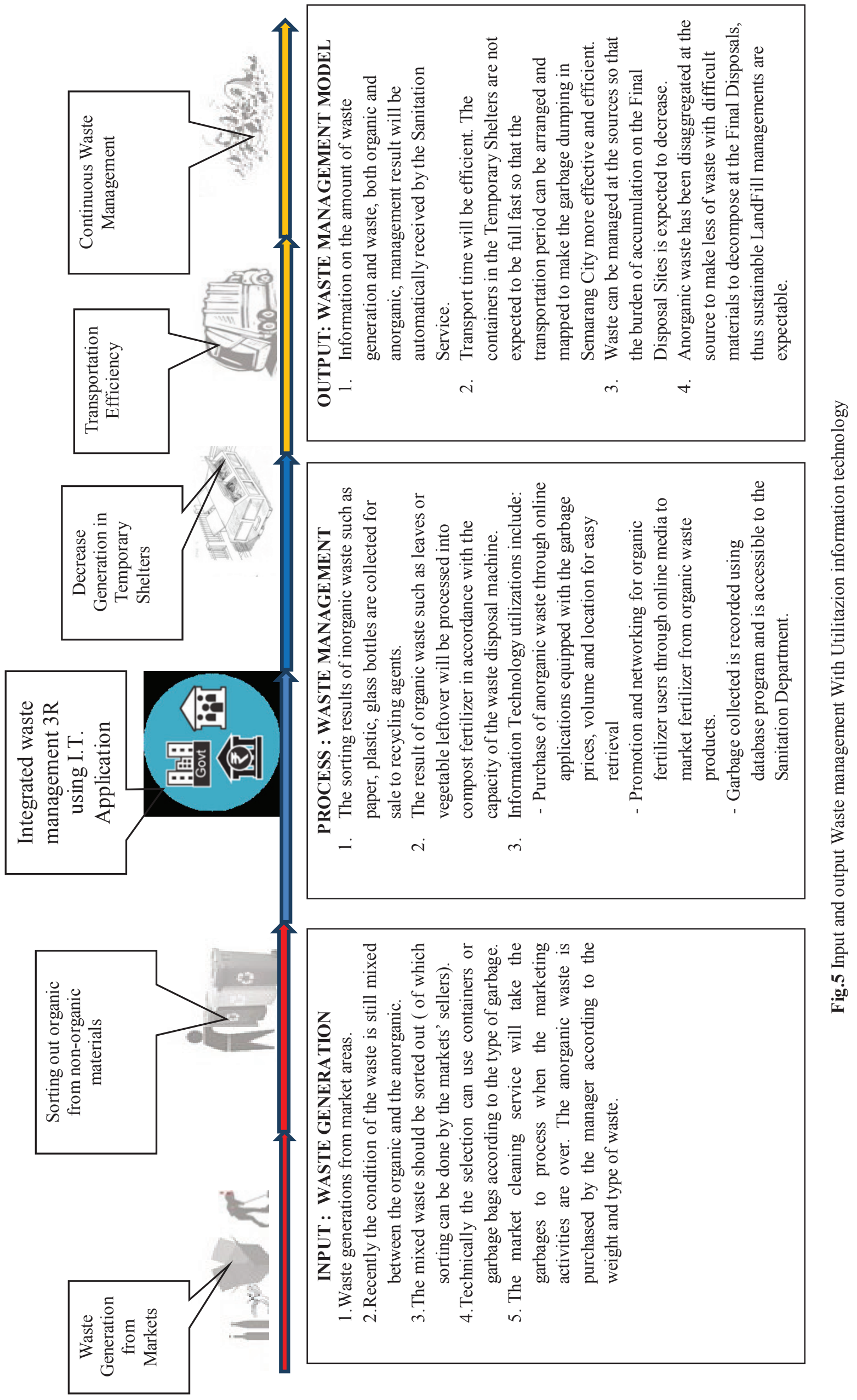




\section{Conclusions}

1. The non-domestic waste generation of Semarang City is an average of $0.24 \mathrm{~kg} /$ person / day in weight unit. The largest contributing source of this waste comes from the hospital waste $(0.49 \mathrm{~kg} / \mathrm{p}$ / d), followed by the market waste $(0.42 \mathrm{~kg} / \mathrm{p} / \mathrm{d})$.

2. The daily generation of the non-domestic waste occurs mostly in the commercial areas, which is of $4.9 \%$ of the total waste generations on Sundays.

3. Non-domestic waste composition of Semarang City shows that the most waste is organic garbage with $62 \%$ percentage consisting of food waste and leaves. The rest of $38 \%$ is inorganic waste in the form of paper, plastic and so on.

4. Information System Management model based on Information Technology can simplify and streamline waste management. This is in the manner that the output system can generate information about the state of waste and handling mechanism based on certain criteria without having to do repetitive data processing.

5. A system model based on information technology can avoid data inconsistencies and can reduce files and time of recording garbage handling.

\section{Suggestion}

The implementation of the waste management policy direction can be an early model to be tested in Semarang City for further research that can be developed at the national level.

\section{Reference}

1. T. Karak, R. M. Bhagat, and P. Bhattacharyya, Crit. Rev. Environ. Sci. Technol., vol. 42, no. 15, pp. 1509-1630, (2012).

2. Central Of Statistic ( BPS), "Percentage of Households by Province and Treatment of Sorting Waste Easy to Decompose and Not Easy to Decompose." 2015.

3. S. E. Vergara and G. Tchobanoglous, Municipal Solid Waste and the Environment: A Global Perspective, vol. 37, no. 1. (2012).

4. Sudharto P Hadi, Quantitative Social Research Methods, Quantitative and Action Studies. (1997).

5. W. Wardiana, Univ. Komput. Indones., (2002). 